\title{
Thyroid Gland Mucinous Follicular Adenoma
}

National Cancer Institute

\section{Source}

National Cancer Institute. Thyroid Gland Mucinous Follicular Adenoma. NCI Thesaurus.

Code C46116.

A thyroid gland adenoma composed of follicles and characterized by the presence of abundant extracellular mucin. 